\title{
Vascular ring connector-related pseudoaneurysm of the descending aorta
}

\author{
Jer-Shen Chen, MD, Chun-Yang Huang, MD, and Jih-Hsin Huang, MD
}

\begin{abstract}
A 60-year-old man with type A acute aortic dissection underwent aortic valve replacement, ascending aorta grafting, and implantation of 2 vascular ring connectors (Vasoring; Sunwei Technology Co, Taipei, Taiwan) in the descending aorta. The vascular ring connectors were put into the descending aorta during open distal anastomosis of the ascending aorta. The proximal ring was fixed at the proximal descending aorta. The distal ring was pulled down and fixed at the retrocardiac descending aorta after lifting the heart upward. The schematic view of the vascular ring connectors is shown in Figure 1. His postoperative recovery was uneventful.
\end{abstract}

Three years later, he presented to the emergency department because of massive hematemesis and near syncope. He had no fever or leukocytosis. An upper gastrointestinal

\footnotetext{
From the Department of Cardiovascular Surgery, Far Eastern Memorial Hospital, New Taipei City, Taiwan.

Disclosures: Authors have nothing to disclose with regard to commercial support.

Received for publication Dec 17, 2013; revisions received Jan 28, 2014; accepted for publication Feb 2, 2014; available ahead of print March 6, 2014.

Address for reprints: Jer-Shen Chen, MD, Department of Cardiovascular Surgery, Far Eastern Memorial Hospital, 13F, No 21, Sec 2, Nan-Ya S Rd, Banqiao, New Taipei City 220, Taiwan (E-mail: jershen@gmail.com).

J Thorac Cardiovasc Surg 2014;148:3236-7

$0022-5223 / \$ 36.00$

Copyright (C) 2014 by The American Association for Thoracic Surgery

http://dx.doi.org/10.1016/j.jtcvs.2014.02.019
}

endoscopy disclosed a pulsatile mass causing external esophageal compression (Figure 2, $A$ and $B$ ). Computed tomography demonstrated a disruption of the distal vascular ring connector in the retrocardiac descending aorta (Figure 3,A). Thoracic stent graft placement successfully sealed the aortic disruption (Figure 3, $B$ and $C$ ). Four days after stent graft coverage of the disruptive thoracic aorta, repeated endoscopy showed rapid resolution of the esophageal compression (Figure 2,C). The patient resumed oral intake without additional complications.

Previously, the vascular ring connector had been reported in the treatment of acute aortic dissection in the Journal. ${ }^{1,2}$ No pseudoaneurysm was found during the follow-up period. However, it is possible that the "tightened" aortic tissue around the vascular ring connector could have become weak and thus would be subject to late disruption. Our images should remind cardiothoracic surgeons to continue monitoring these patients even years after the initial operation.

\section{References}

1. Wei J, Chang CY, Chuang YC, Sue SH, Lee KC, Tung D. A new vascular ring connector in surgery for aortic dissection. J Thorac Cardiovasc Surg. 2009;138: 674-7.

2. Wei J, Chang CY, Chuang YC, Sue SH, Lee KC, Wu CW, et al. Midterm results of vascular ring connector in open surgery for aortic dissection. J Thorac Cardiovasc Surg. 2012;143:72-7

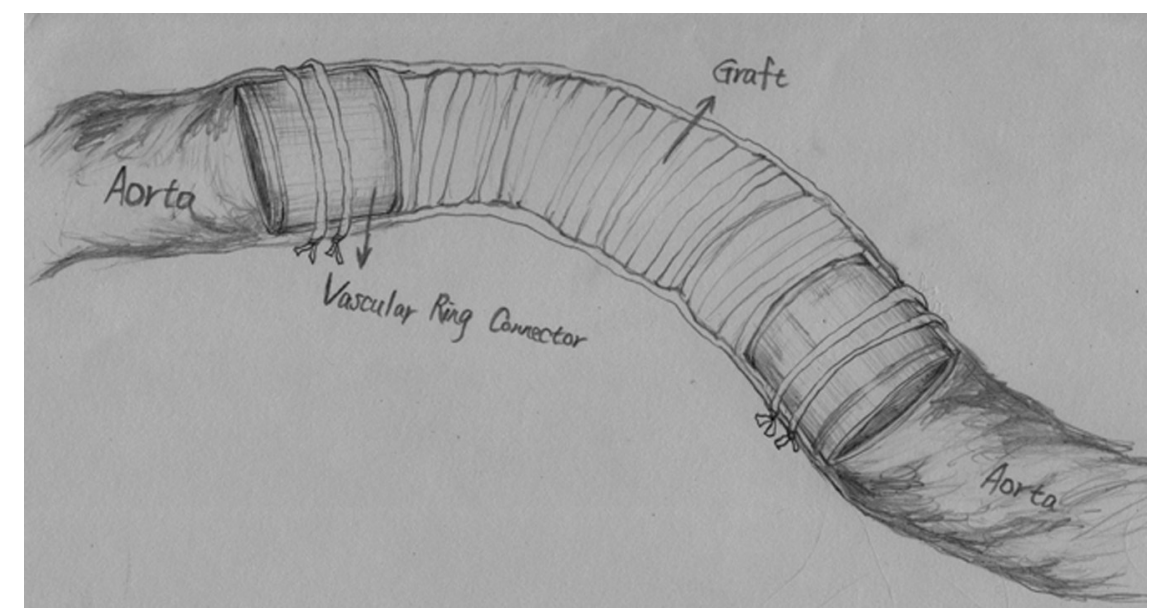

FIGURE 1. Two vascular ring connectors were connected with a vascular graft. The metallic vascular ring connectors could be tied with the aorta, instead of suturing, to decrease the operation time and eliminate anastomotic bleeding. 


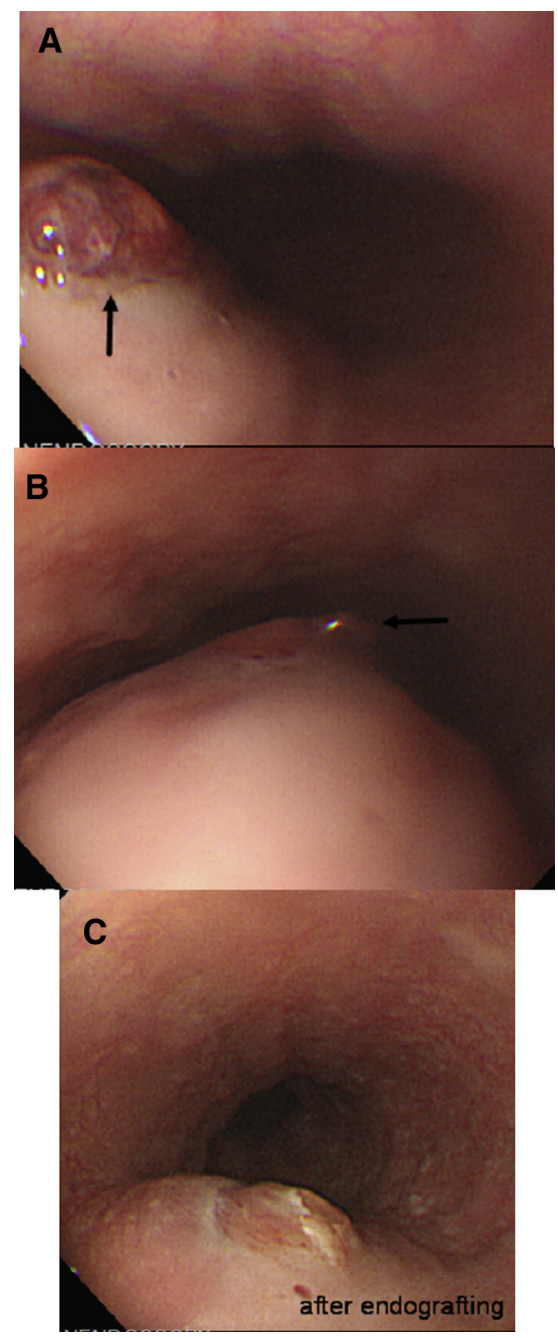

FIGURE 2. A and B, Endoscopy revealed a large, pulsatile mass that had bulged into the lower esophagus, causing external compression (arrow). $\mathrm{B}$, Intermittent bleeding was also noted (arrow). Four days after stent graft coverage, the esophageal compression had resolved significantly. C, The mucosal lesion also appeared to have healed.

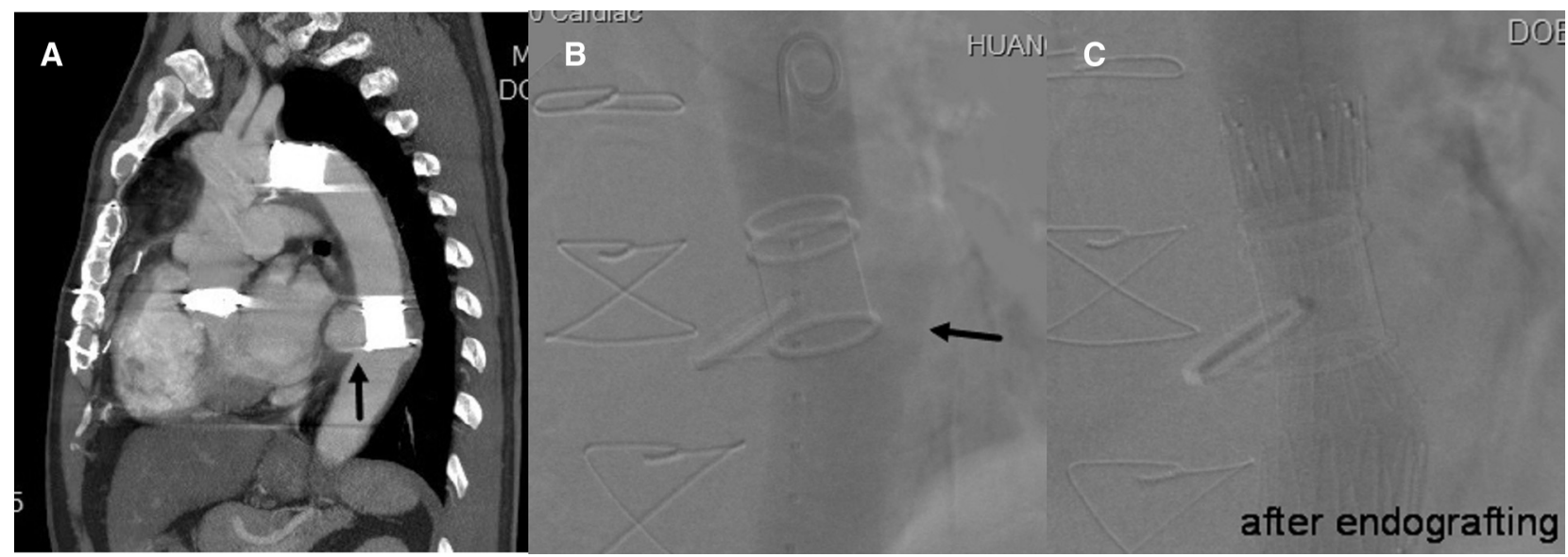

FIGURE 3. A, Computed tomography demonstrated distal disruption of the vascular ring connector in the retrocardiac descending aorta with pseudoaneurysm formation (arrow). B and C, The disrupted aorta was well covered by a stent graft. 